\title{
Residue levels and dissipation behaviors of chlorpyrifos in black pepper berries and soil
}

\author{
Yap, C.A. and Jarroop, Z. \\ Research and Development Division, Malaysian Pepper Board, Lot 1115 Jalan Utama, Pending Industrial \\ Area, 93916 Kuching, Sarawak, Malaysia
}

\author{
Article history: \\ Received: 11 July 2018 \\ Received in revised form: 18 \\ September 2018 \\ Accepted: 30 September 2018 \\ Available Online: 6 \\ November 2018
}

Keywords:

Black pepper,

Residue,

Chlorpyrifos,

Maximum residue limit,

Pre-harvest interval

DOI:

https://doi.org/10.26656/fr.2017.2(6).127

\begin{abstract}
Residue trials of chlorpyrifos in black pepper were conducted to estimate the pre-harvest interval and maximum residue limit for one fruiting cycles. The experimental trials were conducted at five commercial grower's plot located at Serian, Padawan, Sri Aman, Johor and Perak. Each farm was divided into 3 plots with each plot contained 30 mature vines. The first and second plots were treated with chlorpyrifos using manufacturer recommended rate and two-time maximum recommended rate respectively. The third plot was served as non-treated control plot. The insecticide was applied at monthly interval throughout the production cycle using a motorized sprayer with 8 applications. Pepper berries were randomly collected from each plot at $2 \mathrm{hrs}, 1,3,5,7,9,12$ and 15 days after the last spray. The extraction was carried out using the QuEChERS method and was validated prior to actual analysis. Determination of the chlorpyrifos was carried out by gas chromatography-mass spectrometry. Satisfactory recoveries ranging between $80-120 \%$ indicated that the method developed was valid for subsequent analysis. The limits of quantification for chlorpyrifos were $0.01 \mathrm{mg} \mathrm{kg}^{-1}$, respectively. Results showed that chlorpyrifos residues were at the low level with the residue value ranging between $<10 \mu \mathrm{g} /$ $\mathrm{kg}$ to $392.07 \mu \mathrm{g} / \mathrm{kg}$. Dissipation of chlorpyrifos in black pepper berries followed first-order kinetics, and the mean half-lives were 1.41 days after the last treatment. The results also indicated that pepper berries could be safely consumed after 13 days of application. The determined value of the proposed MRL for chlorpyrifos was $0.5 \mathrm{mg} / \mathrm{kg}$.
\end{abstract}

\section{Introduction}

In Malaysia, pepper is grown predominantly in the state of Sarawak, which accounts for $98 \%$ of the country's production. The remaining $2 \%$ is from Sabah and Peninsular Malaysia. Annual pepper production in Malaysia has decreased from $27,000 \mathrm{mt}$ in 2016 to $25,000 \mathrm{mt}$ in 2017 and the average production now is in the region of $22,000 \mathrm{mt}$. There is a number of reasons for the decrease in annual pepper production, with insect pest infestation constituting the most important limiting factor.

A number of insects have been recorded as pests of pepper (Pillai, 1978; Kueh, 1979). Among all the pest available, three species are considered to be economically important, they are Lophobaris piperis, Diconocoris hewetti and Dasynus piperis (Fatimah et al., 2003). The others are occasional or minor pests (Anandaraj and Sarma, 1994)

Method of control for insect pests in pepper farms in
Sarawak had largely depended on the chemical application (Wong, 2002). These practices had not only increased the cost of production greatly but also pose a threat to the health of pepper farmers themselves. This finding was further supported research reported by UNDP (2001) who stated that the farm workers in the fields are at high risk of being poisoned due to the injudicious dependence on pesticides by untrained growers. The practices also help to increase the dissipation of toxic chemicals into the environment and cause ground and surface water pollution (Rajinder et al., 2013).

Around 2.5 million tons of pesticides are being applied worldwide each year (Pimentel, 1995; FAO, 2000) and continue on increasing with due course of time (WHO, 2014). Presently over 44 types of insecticides, 104 types of fungicides and 112 types of weedicides are being used in Pepper industry (Anonymous, 2012). The heavy usage of pesticides created a great human health concern especially in case 
of pepper which is being consumed either raw or without much processing or storage (Abou-Arab, 1999; Kumari Beena et al., 2003).

With the increase in the awareness for a safer and healthier environment, serious efforts should be geared towards monitoring the dissipation pattern of pesticides in pepper under field condition to ensure food safety, particularly for consumption and export. Considering the nutritional and economic importance of pepper crop and harmful effects of synthetic insecticides on human health, the present study was designed to determine the chlorpyrifos residual persistence behavior and to determine the maximum residue level (MRL) and preharvest interval (PHI) of chlorpyrifos after the application in order to confirm their suitability for human consumption.

\section{Materials and methods}

\subsection{Study plot, treatment and sampling}

Five supervised residue trials were conducted for one pepper production cycle (flowering stage to harvesting stage) at five commercial grower's plots throughout Malaysia from 2015-2016 namely Padawan, Serian, Sri Aman, Johor and Perak. Chlorpyrifos-EC $38.7 \%$ was applied by foliar spraying at a rate of $0.4 \mathrm{~kg}$ a.i./ha and $0.8 \mathrm{~kg}$ a.i./ha. The plots, having 30 mature pepper vines (5 years old vines) each, were selected and treated with chlorpyrifos using the manufacturer's recommended rate $(0.40 \mathrm{~kg} \mathrm{a.i} / \mathrm{ha})$ and two-time maximum recommended rate $(0.80 \mathrm{~kg}$ a.i/ha). Pepper vine of the variety "Kuching" was planted with a spacing of $2.1 \mathrm{~m}$ between the row and $2.1 \mathrm{~m}$ within the row, with a population of 2,000 plants per ha. The three (3) treatments consisted of T1: Application with $0.40 \mathrm{~kg}$ a.i/ha of chlorpyrifos pesticide (standard dose); T2: Application with $0.80 \mathrm{~kg}$ a.i/ha (double dose) of chlorpyrifos pesticide and T3: untreated control plot. The pesticide was applied with a motorized sprayer at monthly intervals up to a maximum of 8 applications (complete fruiting cycles) before harvesting. The development of the pepper berries to maturity took eight months from flowering to full ripeness.

After completion of treatment application, approximately $500 \mathrm{~g}$ of green pepper berries were randomly collected from the plots at $2 \mathrm{hrs}, 1,3,5,7,9$, 11,13 and 15 days after the last treatment. The 5 field experiments have provided information on chlorpyrifos residue dissipation pattern in which samples are taken at intervals during the period from the last applications of the pesticide to normal harvest.

The pepper berries were then separated from pepper spike right after harvesting. The separated pepper berries were then undergo blanching processing by soaking the pepper berries in boil water for $1 \mathrm{~min}$ and drying for 2-3 days following accepted practices, with the moisture content less than $12 \%$ (ASTA 2.0). The samples finally sent to MPB quality laboratory immediately for residue extraction and analysis.

For the analysis of chlorpyrifos pesticide residue, this pesticide standard was purchased from Sigma Aldrich. All organic solvents used were of analytical and residue grade and obtained from J.T. Baker, Philipsburg, USA. Stock solution $\left(500 \mathrm{mgL}^{-1}\right)$ was prepared in hexane at store in freezer at $4^{\circ} \mathrm{C}$. Working solution at concentrations of $0.01,0.1$ and $0.5 \mathrm{mgL}^{-1}$ of pesticides was prepared by diluting the appropriate amount of stock solution with hexane and store in freezer at $4^{\circ} \mathrm{C}$.

\subsection{Method development and validation}

For recovery study, ground black pepper sample was fortified with a known amount of chlorpyrifos active ingredient standards. An appropriate amount of chlorpyrifos standard was spiked onto pepper samples to obtain the recoveries at $0.01,0.1$ and $0.5 \mathrm{mg} \mathrm{L}^{-1}$ concentration. Three replicates were prepared for each sample. Recovery of chlorpyrifos was calculated using the following equation:

Recovery of active ingredient $=$ Detected active ingredient $(\mathrm{mg} / \mathrm{kg}) /$ spiked active ingredient $(\mathrm{mg} / \mathrm{kg}) \mathrm{x}$ 100

Recovery between $70-120 \%$ indicated the method suitability in determining analyte quantitatively (Holland et al., 2000).

\subsection{Analysis of pesticides}

Extraction of chlorpyrifos residues from pepper berries was conducted by using QuEChERS method (Anastassiades et al., 2003). A $2.5 \mathrm{~g}$ of ground pepper berries was transferred into a $250 \mathrm{ml}$ bottle and homogenized with $7.5 \mathrm{~mL}$ of water, $10 \mathrm{~mL}$ of acetonitrile, $4 \mathrm{~g}$ of magnesium sulphate and $1 \mathrm{~g}$ of sodium chloride. The mixture was stirred for 15 mins under slow agitation. The homogenous solution was finally centrifuged under refrigeration at $4000 \mathrm{rpm}$ for five minutes. Then, $3 \mathrm{~mL}$ of supernatant liquid was collected and approximately $1.2 \mathrm{~g}$ of magnesium sulphate and $0.4 \mathrm{~g}$ of Z-Sept were added. The mixture was centrifuged for 5 mins and $6 \mathrm{~mL}$ of the clean extract was diluted with $600 \mathrm{~mL}$ of water. The diluted extract was analyzed by using gas chromatography-mass spectrometry (GCMS). 


\subsection{MRL estimation}

A European Union method was employed for the calculation of MRL values (Hyder et al., 2003). The estimation was based on the equation shown below:

$\mathrm{MRL}=\mathrm{R}=\mathrm{KS}$

Where $\mathrm{R}=$ Mean of $\mathrm{HR}^{* *}$ (Highest Residue after PreHarvest Interval, $\mathrm{PHI}) ; \mathrm{K}=\mathrm{One}$-sided tolerance factor for normal distribution with $95 \%$ confidence interval; and $\mathrm{S}=$ the standard deviation of HR after PHI.

\section{Results and discussion}

\subsection{Recovery and detection limits}

The recovery experiments were conducted on untreated pepper berries fortified with 3 spiking level of $0.01,0.1$, and $0.50 \mathrm{mg} \mathrm{kg}$. The recoveries of the chlorpyrifos were repeated in 3 replicates to confirm the validity of the method. The recovery percentage of chlorpyrifos was ranged between $80.0-120.0 \%$ with relative standard deviation (RSD) of $<4.5 \%$ indicated that the analytical method used was effective for subsequent analysis (Table 1). The response showed a good linearity with the correlation coefficients $\left(R^{2}\right)$ value of $\mathrm{R}^{2}=0.998$. The limits of detection (LOD) and limits of quantification (LOQ) of the analytical method for chlorpyrifos in pepper berries were $0.011 \mu \mathrm{g} \mathrm{mL} L^{-1}$ and $0.01 \mathrm{mg} \mathrm{kg}^{-1}$, respectively. The LOQ is the lowest level of spiking $(10 \mu \mathrm{g} / \mathrm{kg})$ that gives acceptable recovery of $80.0-120.0 \%$ and precision relative standard deviation of recoveries $<15 \%$. These results indicated that the QuEChERS extraction method, followed by GCMS analysis is a valid method for chlorpyrifos residue determination in pepper. The example of the calibration curve (for quantification of detected residue) with good linearity $\left(\mathrm{R}^{2}=0.998\right)$ is shown in Figure 1.

\subsection{Residue level of chlorpyrifos}

Table 2 summarizes the residue level of chlorpyrifos from 5 supervised trial located at different locations. The results obtained showed that the initial residue deposition in a standard dose of field treated pepper after the last treatment was low with the residue value ranged between $<10 \mu \mathrm{g} / \mathrm{kg}$ to $392.07 \mu \mathrm{g} / \mathrm{kg}$. The highest residue value was detected in Perak farm with the residue value of $392.07 \mu \mathrm{g} / \mathrm{kg}$. On average, the residue detected in all trial plot was below $300 \mu \mathrm{g} / \mathrm{kg}$ except for Perak farm. This scenario might probably due to low rainfall at the Perak farm with an annual rainfall of $1500 \mathrm{~mm}$ as compared to Sarawak of $3900 \mathrm{~mm}$ annually (Department of Meteorology Malaysia, 2018). Therefore, the pesticide washout effect on Perak farm was not as good as pepper condition in Sarawak. Under double-dose treatment, the

Table 1. Percentage recoveries of chlorpyrifos from spiked pepper berries

\begin{tabular}{cccccccc}
\hline \multirow{2}{*}{ Active Ingredient } & \multirow{2}{*}{ Spike Concentration } & \multicolumn{4}{c}{ Percentage recovered (\%) } & \multirow{2}{*}{ SD } & \multirow{2}{*}{ \% RSD } \\
\cline { 3 - 6 } & & R1 & R2 & R3 & Average & & \\
\hline \multirow{3}{*}{ Pepper berries } & 0.01 & 80 & 83.1 & 85.6 & 82.9 & 2.81 & 3.38 \\
& 0.1 & 118.6 & 120 & 110.8 & 116.5 & 4.96 & 4.26 \\
\multirow{2}{*}{ Soil } & 0.5 & 84.9 & 92.5 & 90.5 & 89.3 & 3.94 & 4.41 \\
& 0.01 & 80 & 85.3 & 81.5 & 82.3 & 2.73 & 3.32 \\
& 0.1 & 105.8 & 110.7 & 103.5 & 106.7 & 3.68 & 3.45 \\
\hline
\end{tabular}

$\mathrm{SD}=$ Standard deviation; $\mathrm{RSD}=$ Relative standard deviation

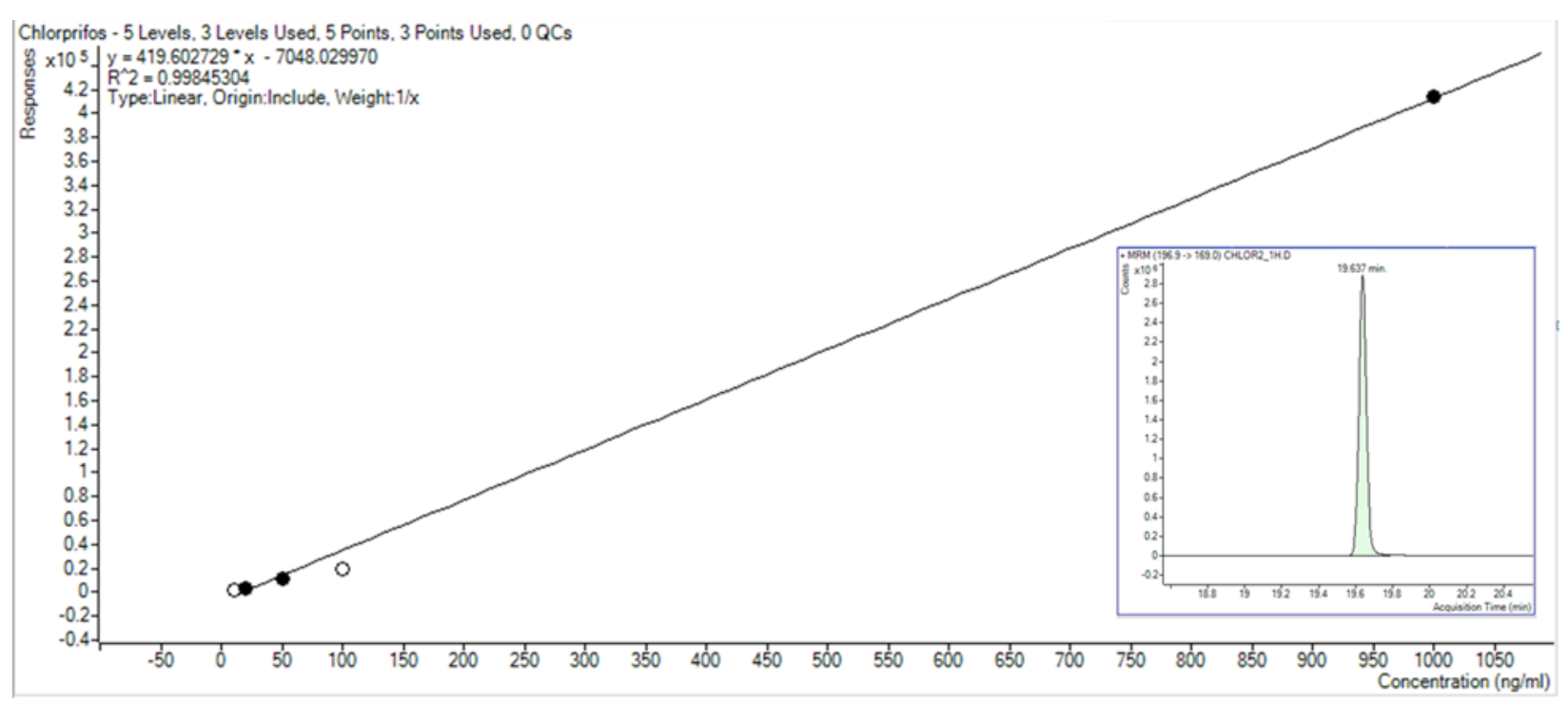

Figure 1. Calibration curve of chlorpyrifos residue 
Table 2. Residue data summary from supervised trials of chlorpyrifos in pepper berries

\begin{tabular}{|c|c|c|c|c|c|}
\hline \multirow{2}{*}{ Trial } & \multirow{2}{*}{ Control } & \multicolumn{2}{|c|}{$0.40 \mathrm{~kg} \mathrm{a.i} / \mathrm{ha}$ (Standard dose) } & \multicolumn{2}{|c|}{$0.80 \mathrm{~kg}$ a.i $/$ ha (Double dose) } \\
\hline & & Residue $(\mu \mathrm{g} / \mathrm{kg})$ & Sampling interval (DAT) & Residue $(\mu \mathrm{g} / \mathrm{kg})$ & Sampling interval (DAT) \\
\hline \multirow{8}{*}{1 (Serian) } & \multirow{8}{*}{ ND } & 219.90 & 2 hour & 565.60 & 2 hour \\
\hline & & 207.16 & 1 day & 228.92 & 1 day \\
\hline & & 46.51 & 3 days & 29.68 & 3 days \\
\hline & & 38.93 & 5 days & 24.48 & 5 days \\
\hline & & 27.57 & 7 days & 33.63 & 7 days \\
\hline & & 27.59 & 9 days & 27.60 & 9 days \\
\hline & & 16.90 & 11 days & 16.94 & 11 days \\
\hline & & $<10$ & 13 days $* *$ & $<10$ & 13 days $* *$ \\
\hline \multirow{8}{*}{2 (Padawan) } & \multirow{8}{*}{ ND } & 266.15 & 2 hour & 630.67 & 2 hour \\
\hline & & 229.55 & 1 day & 278.23 & 1 day \\
\hline & & 140.09 & 3 days & 34.81 & 3 days \\
\hline & & 36.30 & 5 days & 23.75 & 5 days \\
\hline & & 26.48 & 7 days & 16.80 & 7 days \\
\hline & & 27.72 & 9 days & 29.53 & 9 days \\
\hline & & 16.83 & 11 days & 16.81 & 11 days \\
\hline & & $<10$ & 13 days $* *$ & $<10$ & 13 days** \\
\hline \multirow{8}{*}{3 (Sri Aman) } & \multirow{8}{*}{ ND } & 296.89 & 2 hour & 588.63 & 2 hour \\
\hline & & 205.10 & 1 day & 260.04 & 1 day \\
\hline & & 117.03 & 3 days & 36.24 & 3 days \\
\hline & & 38.93 & 5 days & 23.45 & 5 days \\
\hline & & 30.81 & 7 days & 33.70 & 7 days \\
\hline & & 28.64 & 9 days & 28.55 & 9 days \\
\hline & & 16.88 & 11 days & 16.92 & 11 days \\
\hline & & $<10$ & 13 days $* *$ & $<10$ & 13 days $* *$ \\
\hline \multirow{8}{*}{4 (Johor) } & \multirow{8}{*}{ ND } & 249.29 & 2 hour & 609.44 & 2 hour \\
\hline & & 114.55 & 1 day & 280.39 & 1 day \\
\hline & & 50.83 & 3 days & 30.16 & 3 days \\
\hline & & 19.61 & 5 days & 32.83 & 5 days \\
\hline & & 23.17 & 7 days & 10.83 & 7 days \\
\hline & & 23.60 & 9 days & 25.41 & 9 days \\
\hline & & 10.87 & 11 days & 10.83 & 11 days \\
\hline & & $<10$ & 13 days** & $<10$ & 13 days $* *$ \\
\hline \multirow{8}{*}{5 (Perak) } & \multirow{8}{*}{ ND } & 392.07 & 2 hour & 647.79 & 2 hour \\
\hline & & 112.69 & 1 day & 264.41 & 1 day \\
\hline & & 58.65 & 3 days & 31.63 & 3 days \\
\hline & & 32.88 & 5 days & 20.87 & 5 days \\
\hline & & 22.45 & 7 days & 29.82 & 7 days \\
\hline & & 28.52 & 9 days & 28.67 & 9 days \\
\hline & & 10.86 & 11 days & 10.84 & 11 days \\
\hline & & $<10$ & 13 days** & $<10$ & 13 days $* *$ \\
\hline Soil at harvest & ND & $<10$ & 13 days & $<10$ & 13 days \\
\hline
\end{tabular}
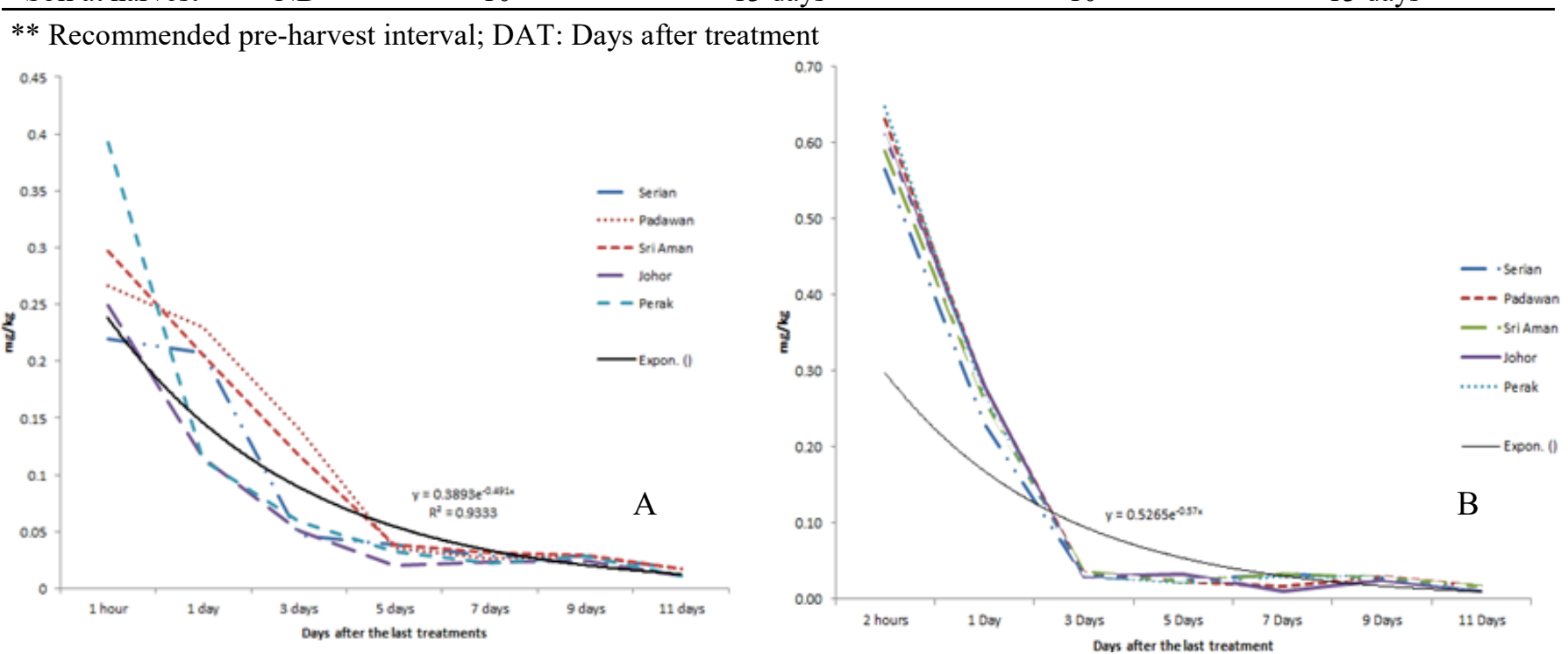

Figure 2. Dissipation of chlorpyrifos in pepper berries treated with standard and double dose concentration (A) Standard dose;

(B) Double dose 
initial residue deposit was considered high as compared to standard dose with the residue value ranged between $<10 \mu \mathrm{g} / \mathrm{kg}$ to $647.79 \mu \mathrm{g} / \mathrm{kg}$. The highest residue was detected in trial plot 5 located at Perak with residue value of $647.79 \mu \mathrm{g} / \mathrm{kg}$. No residues were detected on the control plot. Even though the initial residue was high in both treatments on the first $2 \mathrm{hrs}$ after the last spray, but nearly half of the residue was lost on the day 2 after the last treatment with the mean half-lives of 1.41 days and 0.85 days respectively. The residues, however, were still persisted in the berries for approximately 13 days for both treatments before the readings were below LOQ value. The low residue level of chlorpyrifos detected on standard dose treatment was mainly due to the low dosage used $0.4 \mathrm{~kg}$ a.i/ha and the compound's rapid degradation properties. Since the chlorpyrifos residue was meager, therefore, the degradation processes of chlorpyrifos in black pepper seem to occur through reduction, hydrolysis and photolysis, respectively. At harvest (13 days), the residues of chlorpyrifos in soil were below the LOQ $\left(0.01 \mathrm{mgkg}^{-1}\right)$. Similar observations were also reported earlier by other researchers (Lu et al., 2014; Yuan et al., 2014) who stated that the translocation of chlorpyrifos in plant vascular systems was limited by short residue half live, $\mathrm{DT}_{50}$. Furthermore, the persistence of pesticide residue in pepper vines was also influenced by various environmental factors such as temperature, relative humidity, UV irradiation, metabolism and translocation, application technique and pesticide formulation (Lemus and Abdelghani, 2000). Based on the results obtained, it can be concluded that the high chlorpyrifos dissipation rate in soil could be due to high rainfall accumulation $(>1500 \mathrm{~mm})$ and high humidity $(50-75 \%)$.

\subsection{Dissipation kinetics and safety constants}

The dissipation dynamics of chlorpyrifos on fieldtreated pepper could be described by the following firstorder rate kinetics equation: $\mathrm{Y}=0.3893 \mathrm{e}^{-0.491 \mathrm{X}}$ (single dose, $\quad \mathrm{R}^{2}=0.9333$ ); $\mathrm{Y}=0.5265 \mathrm{e}^{-0.57 \mathrm{X}} \quad$ (double dose, $\mathrm{R}^{2}=0.9738$ ). These results showed that the half-life $\left(\mathrm{DT}_{50}\right)$ value for chlorpyrifos treated with standard and double-dose were on day 1.41 and 0.85 respectively (Figures 2A and 2B). This finding indicated that the degradation rate of chlorpyrifos was considered fast and will not persist in the soil and berries for a long period of time. To further ensure the safety of the pepper berries produce, the post-harvest interval (PHI) was determined based on the method described by Hoskins (1961). PHI is referring to the duration needed by pesticide to degrade to an acceptable level which is considered safe for consumption. Based on data obtained, the chlorpyrifos residue required approximately 13 days to degrade to an undetectable level for both standard and double-dose treatments indicating the PHI is on day 13 after the last spray.

\subsection{Maximum residue level (MRL) estimation}

A European Union method (Hyder et al., 2003) was used in this study to determine the MRL for chlorpyrifos. Based on this method, a minimum of 4 residue trials is needed for MRL establishment with the mean dietary intake of foodstuffs of less than $7.5 \mathrm{~g} /$ person/day. In this case, pepper fell into this category with the mean dietary intake is $6.9 \mathrm{~g} /$ person/day (USDA, 2016, reference number: 02030). Besides, the data entry only involves the residue value collected from a recommended dose as this is the dose that will be used in the pepper industry for pest control.

For MRL determination, only the maximum residue values from each experiment trial were taken as one data point. For those residues reading that are below the limit of quantification (LOQ), the residue value was recorded as $0.01 \mathrm{mg} / \mathrm{kg}$ (LOQ). After correction of the values and consideration of the outliers the mean values $R$ and related standard deviations for the residue figures at each test time and the related standard deviations can be determined. MRL can be calculated according to the formula as shown below:

$$
\begin{aligned}
\text { MRL for chlorpyrifos } & =\mathrm{R}+\mathrm{KS} \\
& =0.285+(4.202 \times 0.06) \\
& =0.53 \mathrm{mg} / \mathrm{kg}
\end{aligned}
$$

Based on European Union method for MRL calculation, the estimated MRL value for chlorpyrifos was 0.5 respectively. This value was further rounded up to 0.2 following the rules set by Codex. Therefore, the proposed MRL of chlorpyrifos in black pepper was 0.5 $\mathrm{mg} / \mathrm{kg}$. The proposed MRL value obtained in this experimental trial was slightly higher than MRL for other fresh crop stated in the Food Act 1983 and Regulations 1985. For example, MRL for chlorpyrifos in leafy vegetables is 1 . This research finding was expected because this residue was get concentrated during sun drying process. This phenomenon could be due to dry weight loss consequent to dehydration. Besides, high molecule stability at high temperature also is another factor contributes to high MRL value in dried pepper berries. In addition, this research finding was further supported by George et al. (2014) who reported that sunlight increases the pesticide residue in dried foodstuff as compared to fresh foodstuff. To further confirm the MRL value generated from this trial, the data regenerated from this trial were further analysis using OECD MRL calculator (OECD, 2014). Based on the result obtained, the results generated from OECD MRL calculator was consistent with the results generated from 
the calculation above indicated that the trial conducted was valid with the MRL value of $0.5 \mathrm{mg} / \mathrm{kg}$ (Figure 3).
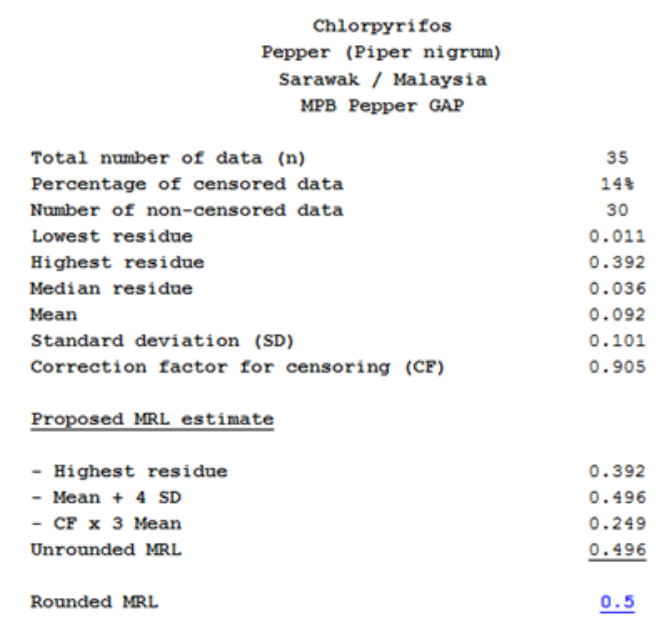

Figure 3. MRL value generated using OECD MRL calculator

\section{Conclusion}

The lack of acceptable MRLs for agriculture commodities by national governments leads to barriers in trade. In order to assure Malaysian pepper industry prosperity, Malaysian Pepper Board has taken an initiative to conduct a research to establish MRLs of pesticides for export commodities. On the basis of present findings, it could be concluded that the preharvest interval for application of chlorpyrifos active ingredient was on day 13 after the last application. A proposed MRL of $0.5 \mathrm{mg} / \mathrm{kg}$ was determined for pepper berries (Piper nigrum L.) based on residue trials data.

\section{Acknowledgments}

The authors wish to thank the Malaysian Pepper Board for financing and making the research possible. Lawrence Ak Tuah, Sang Ak Jam and Wan Ak Ambi are also thanked for excellent technical assistance.

\section{References}

Abou-Arab, A.A.K. (1999). Effect of processing and storage of dairy products on lindane residue and metabolites. Food Chemistry, 64(4), 467-473. https:// doi.org/10.1016/S0308-8146(98)00126-5

Anandaraj, M. and Sarma, Y.R. (1994). Biological control of black pepper diseases. Indian Cocoa Arecanut Spices Journal, 18, 22-23.

Anastassiades, M., Lehotay, S.J., Stajnbaher, D. and Schenck, F.J. (2003). Fast and easy multi-residue method for the determination of pesticide residues in produces by acetonitrile extraction/partitioning and dispersive solid-phase extraction. Journal of AOAC International, 86, 412-431.
Anonymous. (2012). List of registered black pepper pesticides for Malaysian Pesticide Board, p. 1-14. Putrajaya, Malaysia: Department of Agriculture, Malaysia.

Department of Meteorology Malaysia. (2018). Agroclimatic Analysis and Outlook 2017. Annual report, p. 65. Malaysia: Department of Meteorology.

FAO. (2000). Pesticide Residues in Food: Report of the Joint Meeting of the FAO Panel of Experts on Pesticide Residues in Food and the Environment and the WHO Core Assessment Group on Pesticide Residues, p. 45-59. Geneva, Switzerland: FAO.

Fatimah, O., Wong, T.H., Eng, L., Paulus. A.D. and Asmah, S. (2003). XCROP-Pepper: An Expert System for Diagnosing Disease, Pests and Nutritional Disorders of Black Pepper in Sarawak, International Pepper News Bulletin, p. 46-50. Jakarta: International Pepper Community

Food Act 1983 (Act 281) and Regulations (2014). Malaysia: International Law Book Services.

George, X., Chandran, M., George, T., Beevi, S.N., Mathew, T.B., Pau, A., Arimboor, R., Vijayasree, V., Pradeepkumar, G.T. and Rakith, R. (2014). Persistence and effect of processing on reduction of fipronil and its metabolites in chili pepper (Capsicum annum L.) fruits. Environment Monitoring Assessment, 186(9), 5429-5437.

Holland, P.T., Botd, A.J. and Malcolm, C.P. (2011). Performance validation of a multi-residue method for 170 pesticides in kiwifruit. In Fajgeli, A. and Ambrus, A. (Eds). Principle and Practices of Method Validation, p. 29-40 Cambridge, United Kingdom: Royal Society of Chemistry.

Hoskins, W.M. (1961). Mathematical treatment of loss of pesticide residues. FAO Plant Protection Bulletin, 9, 163-168.

Hyder, K., Travis, K.Z., Welsh, Z.K. and Pate, I. (2003). Maximum Residue Level: Fact or fiction? Human and Ecological Risk Assessment, 9(3), 721-740. https://doi.org/10.1080/713609964

Kueh, T.K. (1979). Pest, disease and disorders of black pepper in Sarawak [Bulletin], p. 68. Kuching, Sarawak: Le Ming Press.

Kumari, B., Kumar, R., Madan, V.K., Singh, R., Singh, J. and Kathpal, T.S. (2003). Magnitude of pesticidal contamination in winter vegetables from Hisar, Haryana. Environmental Monitoring and Assessments, 87(3), 311-318. https:// doi.org/10.1023/A:1024869505573

Lemus, R. and Abdelghani, A. (2000). Chlorpyrifos: an unwelcome pesticide in our homes. Reviews on Environmental Health, 15, 421-433. https:// 
doi.org/10.1515/REVEH.2000.15.4.421

Lu, M.X., Jiang, W.W., Wang, J.L., Jian, Q., Shen, Y. and Liu, X.J. (2014) Persistence and Dissipation of Chlorpyrifos in Brassica Chinensis, Lettuce, Celery, Asparagus Lettuce, Eggplant, and Pepper in a Greenhouse. PLoS ONE 9(6), 125-137. https:// doi.org/10.1371/journal.pone.0100556

OECD. (2014). MRL Calculator: Users Guide and White Paper, Serie on Pesticides and Biocides, No. 56 Paris: OECD Publishing. https:// doi.org/10.1787/9789264221567-en.

Pillai, G.B. (1978). Pests of pepper. In Nair, M.K. and Haridasan, M. (Eds.). Proceedings National Seminar on Pepper Central Plantation Crops Research Institute, p. 15-17. Kasaragod: Indian Institute of Spices Research.

Pimentel, D. (1995). Soil Erosion: A Food and Environmental Threat. Environment, Development and Sustainability, 8(1), 119-137. https:// doi.org/10.1007/s10668-005-1262-8

Rajinder, K., Balwinder S., Kousik, M., Abhijit, K. and Preetinder, S.S. (2013). Bioefficacy and fate of fipronil and its metabolites in basmati rice under sub -tropical climate conditions. Crop Protection, 45, 41 -48. https://doi.org/10.1016/j.cropro.2012.11.017

UNDP. (2011). UNDP-GEF: Persistent organic pollutant Resources, GEF. New York: UNDP

USDA. (2016). National Nutrient Database for Standard Reference Legacy Release. Full Report (All Nutrients) 02030, Spices, pepper, black. Retrieved from USDA website: https://ndb.nal.usda.gov/ndb/ foods/show/02030?

fgcd $=\&$ manu $=\&$ format $=$ Full \& count $=\& \max =25 \&$ off set $=\&$ sort $=$ default $\&$ order $=$ asc $\&$ qlookup $=$ black + pep per\% $2 \mathrm{C}+$ spice $\& \mathrm{ds}=\& \mathrm{qt}=\& \mathrm{qp}=\& \mathrm{qa}=\& \mathrm{qn}=\& \mathrm{q}=\&$ ing $=$

WHO. (2014) Public Health Impact of Pesticides Used in Agriculture, p. 88. Geneva: World Health Organization

Wong, M.H. (2002). Fungal diseases of black pepper and their management in Sarawak, Malaysia. Symposium on Pests and Diseases of Pepper, 24 Sept. 2002. Kuching, Malaysia

Yuan, Y., Chen, C., Zheng, C., Wang, X. and Yang, G. (2014) Residue of chlorpyrifos and cypermethrin in vegetables and probabilistic exposure assessment for consumers in Zhejiang Province, China. Food Control, 36(1), 63-68. https://doi.org/10.1016/ j.foodcont.2013.08.008 